\title{
Dominance relationships between S-alleles in self-incompatible Brassica campestris $L$.
}

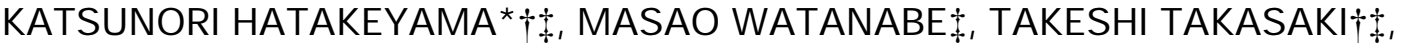 \\ KUNIHIKO OJ IMA $†$ \& KOKICHI HINATA†† \\ $\dagger$ Research Institute of Seed Production Co. Ltd., 6-6-3 Minamiyoshinari, Aoba-ku, Sendai, 989-32 J apan and \\ $\$$ Faculty of Agriculture, Tohoku University, Aoba-ku, Sendai, $981 \mathrm{~J}$ apan
}

\begin{abstract}
Dominance relationships were studied for 249 out of 276 possible pair-wise combinations between $24 S$-alleles of Brassica campestris that had been isolated from two natural populations from Turkey and Japan. Each $F_{1}$ hybrid was test-crossed reciprocally against its respective parental $S$-homozygotes to determine the dominance relationships between the pair of $S$-alleles it contained. The $24 S$-alleles were classified into two groups on the stigma side and three groups on the pollen side. In the stigma, codominance occurred frequently, and dominance or recessiveness seemed to appear according to the combination of $S$-alleles. In the pollen, codominance was less frequent, and there seemed to be a certain hierarchy of the dominance relationships as a whole, although dominance appeared with certain specific combinations of $S$-alleles. Interactions among $24 S$-alleles were different in the stigma and in the pollen. Independent weakening of $S$-alleles was found between 20 pairs in the pollen, but only two in the stigma. This interaction seems to be correlated with recessiveness of $S$-alleles.
\end{abstract}

Keywords: Brassica campestris, dominance relationships, $S$-alleles, sporophytic selfincompatibility.

\section{Introduction}

Self-incompatibility in Brassica species is determined by a single, multiallelic gene, $S$, whose expression in the pollen is sporophytic, the growth of incompatible pollen being arrested on the stigma (Bateman, 1955). Because the incompatibility phenotype of the pollen is determined by the diploid genotype of the pollen parent, the alleles at this locus can display dominance, both in the pollen and the stigma but not necessarily the same for both sides of a cross (Thompson \& Taylor, 1966).

Dominance relationships between $S$-alleles have been investigated in several species of Brassicaceae, including Iberis amara (Bateman, 1954, 1955), Brassica oleracea, B. campestris, Raphanus sativus (Haruta, 1962), R. raphanistrum (Sampson, 1964, 1967) and Sinapis arvensis (Stevens \& Kay, 1989). Dominance relationships in Brassica oleracea have also been investigated in kale (Thompson \& Taylor, 1966), in Brussels sprouts (Ockendon, 1975; Visser et al., 1982) and in cabbage (Wallace, 1979). The relationships among three $S$-alleles, $S_{a}, S_{b}$ and $S_{c}$,

*Correspondence. E-mail: hatake@tree.or.jp can be classified into two categories: linear and nonlinear. When $S_{a}$ is dominant to $S_{b}\left(S_{a}>S_{b}\right)$ and $S_{b}$ is dominant to $S_{c}\left(S_{b}>S_{c}\right)$, if $S_{a}$ is also dominant to $S_{c}$, dominance is linear $\left(S_{a}>S_{b}>S_{c}\right)$, and if $S_{a}$ is not dominant to $S_{c}$, dominance is nonlinear (Thompson \& Taylor, 1966). It has been found that the dominance relationships need not be fully linear and that the dominance of a specific $S$-allele in the pollen can be different from that in the stigma. Furthermore, it has been observed that both incompatible and compatible reactions on the papilla cells of the stigma can be influenced by genetic background, stage of flowering, age of flower and environmental factors (Ockendon, 1975). In contrast, in diploid Ipomoea trifida (Convolvulaceae), which also possesses a sporophytic self-incompatibility system, the pattern of dominance between $28 \mathrm{~S}$-alleles was strongly linear in both the stigma and the pollen (Kowyama et al., 1994).

We have isolated 30 different $S$-allele homozygotes from two distinct naturalized populations of $B$. campestris in Turkey and Japan (Nou et al., 1991, 1993a,b). In this paper, we report the results obtained from an analysis of the dominance relationships between $24 S$-alleles of B. campestris. 


\section{Materials and methods}

\section{Materials}

The $24 S$-homozygotes of $B$. campestris used in the present experiment were taken from those produced by Nou et al. (1991, 1993a,b) from two natural populations from Oguni, Japan and Balcesme, Turkey (Table 1). These $S$-homozygotes were raised twice a year, in the spring and in the autumn in a greenhouse. The seedlings raised in the autumn were vernalized at $9^{\circ} \mathrm{C}$ for 30 days to promote flowering. The flowering period was from April to May in the spring and from October to November in the autumn.

Table 1 The origin of the $S$-alleles used in this investigation of Brassica campestris

\begin{tabular}{ll}
\hline Japanese strains & Turkish strains \\
\hline$S_{24}\left(S_{12 \mathrm{j}}\right)$ & $S_{21}(82-9 \mathrm{t})$ \\
$S_{25}(38-7 \mathrm{j})$ & $S_{30}(32-14 \mathrm{t})$ \\
$S_{26}(2-10 \mathrm{j})$ & $S_{31}(42-5 \mathrm{t})$ \\
$S_{28}\left(S_{\mathrm{j} j}\right)$ & $S_{32}(24-8 \mathrm{t})$ \\
$S_{29}(7-5 \mathrm{j})$ & $S_{33}(20-2 \mathrm{t})$ \\
$S_{34}(9-1 \mathrm{j})$ & $S_{35}(46-12 \mathrm{t})$ \\
$S_{36}(9-14 \mathrm{j})$ & $S_{37}(45-9 \mathrm{t})$ \\
$S_{41}(7-6 \mathrm{j})$ & $S_{38}(22-7 \mathrm{t})$ \\
$S_{43}\left(S_{8 j}\right)$ & $S_{40}(85-3 \mathrm{t})$ \\
$S_{44}(12-2 \mathrm{j})$ & $S_{47}(26-6 \mathrm{t})$ \\
$S_{45}(11-12 \mathrm{j})$ & $S_{48}(45-3 \mathrm{t})$ \\
$S_{46}(1-6 \mathrm{j})$ & $S_{49}(45-9 \mathrm{t})$ \\
\hline
\end{tabular}

j, $S$-alleles isolated from Oguni, Japan.

t, $S$-alleles isolated from Balcesme, Turkey.

The code number in brackets shows the strain number in

Nou et al. (1991, 1993a,b).
Selfed seed was obtained by bud-pollination and hybrid seed was obtained for 249 out of 276 possible combinations between the $24 S$-homozygotes in the spring of 1992. Dominance relationships between $S$-alleles of the $\mathrm{F}_{1} \mathrm{~s}$ were determined by test-crosses of the $\mathrm{F}_{1}$ to its respective parental $S$-homozygotes, as will be described later. Out of $249 \mathrm{~F}_{1}$ combinations, 66 combinations were determined in the autumn of 1992, 112 in the spring of 1993, and 71 in the autumn of 1993. In addition, $F_{2}$ seeds of the heterozygote, $S_{24} S_{25}$, were also obtained by bud-pollination, and diallel pollination between the progeny was performed to check the consistency of dominance relationships that were determined by $F_{1}$ testpollinations.

\section{Test-crosses for the determination of dominance relationships}

In the test-cross pollinations, pollinated flowers were cut at the peduncle and stood on 1 per cent solid agar for $24 \mathrm{~h}$ under room conditions. Thereafter, pistils of the pollinated flowers were immersed in $1 \mathrm{~N} \mathrm{NaOH}$ for $1 \mathrm{~h}$ at $60^{\circ} \mathrm{C}$, stained with basic aniline blue $\left(0.1 \mathrm{M} \mathrm{K}_{3} \mathrm{PO}_{4}, 0.1\right.$ per cent aniline blue), and mounted in 50 per cent glycerol (fluorescence microscope grade; Kho \& Baer, 1968). Pollen tube behaviour was observed under a Nikon UV fluorescence microscope with an excited filter of $330-380 \mathrm{~nm}$ and a barrier filter of $420 \mathrm{~nm}$ (Wong et al., 1994). Three flowers were used in each cross combination on each occasion (Table 2) and observations were generally replicated twice or three times for each cross combination on different dates. The degree of compatibility in each test-pollination was classified into three categories based on the pollen tube penetration to the stigma. When more

Table 2 Dominance relationships between $S$-alleles in test-crosses of Brassica campestris

\begin{tabular}{lccccc}
\hline Test-cross combination & & & & & \\
$S_{a} S_{a} \times S_{a} S_{b}$ & - & + & - & + & + \\
$S_{a} S_{b} \times S_{a} S_{a}$ & - & - & + & + & - \\
$S_{b} S_{b} \times S_{a} S_{b}$ & - & - & - & - & + \\
$S_{a} S_{b} \times S_{b} S_{b}$ & - & - & - & - & - \\
Dominance relationship & & & & & \\
Pollen & $S_{a}=S_{b}$ & $S_{a}<S_{b}$ & $S_{a}=S_{b}$ & $S_{a}<S_{b}$ & $S_{a}<S_{b}, S_{a}>S_{b}{ }^{1}$ \\
Stigma & $S_{a}=S_{b}$ & $S_{a}=S_{b}$ & $S_{a}<S_{b}$ & $S_{a}<S_{b}$ & $S_{a}=S_{b}$ \\
\hline
\end{tabular}

+ , compatible; - , incompatible.

$S_{a}<S_{b}, S_{b}$ is dominant to $S_{a} ; S_{a}=S_{b}$, alleles are codominant.

${ }^{1}$ Such cases show low expressivity of $S$-genes in a heterozygous plant. This relationship resembles the independent weakening described by Visser $e t$ al . (1982). 
than 20 pollen tubes penetrated the stigmatic papillae, the pollination was classified as compatible; when five or fewer pollen tubes penetrated, it was classified as incompatible; and when between five and 20 pollen tubes penetrated the stigma, it was classified as partially compatible.

\section{Results}

\section{Pollination test}

Reciprocal test-pollinations between an $\mathrm{F}_{1}$ plant and each of its parental homozygotes were carried out to determine the dominance relationships between the pair of $S$-alleles, as exemplified in Table 2. All the $\mathrm{F}_{1}$ plants tested were self-incompatible.

Entirely consistent results were obtained over replicates for 83.2 per cent of total $S$-allelic combinations in the stigma and 65.2 per cent in the pollen. These combinations could be clearly classified as codominant or dominant. Some unclear cases, where the data from one flower were inconsistent with the other replicates, were found in 11.6 per cent of the stigmatic and 20.0 per cent of the pollen combinations of $S$-alleles; these were classified as incompletely codominant or dominant. In total, codominance or dominance of the $S$-allelic combinations were found for 94.8 per cent of the total combinations in the stigma and 85.2 per cent in the pollen.

In some other cases, a cross between one parent and the $F_{1}$ was incompatible, whereas the cross between the other parent and the $F_{1}$ gave inconsistent results, sometimes being compatible and other times incompatible. It was considered that the expression of one $S$-allele was complete, but that of the other $S$-allele was insufficient to determine codominance or dominance. Such cases were found in 4.4 per cent of the pairs in the stigma and 6.8 per cent of the pairs in the pollen. These $S$-allelic pairs were classified as nondeterminable, and are shown as ' $\mathrm{X}$ ' in Figs 1 and 2.

For 0.8 per cent (two $S$-pairs) of the combinations in the stigma and 8.0 per cent (20 S-pairs) in the pollen, $S$-heterozygous plants, although self-incompatible, showed compatibility to both parental

\begin{tabular}{|c|c|c|c|c|c|c|c|c|c|c|c|c|c|c|c|c|c|c|c|c|c|c|c|c|c|}
\hline & \multicolumn{16}{|c|}{ CD-s } & \multicolumn{8}{|c|}{ DR-s } \\
\hline & & S40t & $S 29_{j}$ & $S 49 t$ & $S 36 j$ & $S 37 t$ & $S 38 t$ & $S 47 t$ & $S 33 t$ & $S 44 j$ & $S 32 t$ & $S 48 t$ & $S 46 j$ & $S 26 j$ & $S 45 j$ & $S 34 j$ & $S 24 j$ & $S 35 t$ & $S 41 j$ & $S 28 j$ & $S 43 j$ & S31t & $S 30 t$ & $S 21 t$ & $S 25 j$ \\
\hline \multirow{16}{*}{ CD-s } & $S 40 t$ & & c & C & c & c & c & c & c & C & c & c & & c & c & c & c & c & c & C & c & c & $x$ & c & c \\
\hline & $S 29_{j}$ & c & & C & C & C & C & C & C & C & C & C & $x$ & C & C & C & C & c & C & C & c & C & C & C & C \\
\hline & $S 49 t$ & c & c & & c & C & c & c & C & C & c & $x$ & & c & C & c & c & $x$ & c & & c & c & C & c & C \\
\hline & $S 36 j$ & C & C & C & & C & C & c & C & C & c & C & C & C & C & c & c & C & $x$ & it & C & C & C & D & C \\
\hline & $S 37 t$ & C & C & C & c & & c & C & C & C & c & c & & c & c & C & c & & C & C & c & c & C & c & D \\
\hline & $S 38 t$ & C & C & c & c & C & & & c & C & C & C & & $x$ & c & c & c & & c & c & $x$ & c & c & c & D \\
\hline & $S 47 t$ & c & c & c & c & c & & & c & C & & c & & c & & c & & & c & & c & C & C & c & D \\
\hline & $S 33 t$ & c & c & c & c & C & C & c & & c & c & c & & c & c & c & c & c & & c & c & c & D & c & C \\
\hline & $S 44 j$ & c & c & c & c & C & c & C & C & & C & c & c & c & C & c & $x$ & c & c & c & C & $R=$ & c & D & c \\
\hline & $S 32 t$ & C & C & c & c & C & c & & C & c & & C & & C & C & c & c & c & c & & $R$ & c & & c & c \\
\hline & $S 48 t$ & C & c & $x$ & C & C & C & c & C & C & c & & & c & C & C & c & C & c & $\mathrm{R}$ & C & C & C & $\Omega$ & C \\
\hline & $S 46 j$ & & $x$ & & C & & & & & C & & & & c & c & c & C & & i & $\mathrm{R}$ & c & & & & c \\
\hline & $S 26 j$ & c & C & C & c & C & $x$ & C & C & C & c & C & c & & C & c & c & D & c & R & C & C & C & $R$ & c \\
\hline & $S 45 j$ & c & C & c & C & C & c & & C & C & C & C & C & C & & c & c & c & C & c & $x$ & 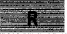 & c & मे & D \\
\hline & $S 34 j$ & c & C & c & c & C & c & c & C & C & C & C & c & c & c & & C & c & c & c & C & D & D & $x$ & C \\
\hline & $S 24 j$ & C & C & C & C & C & C & & C & $x$ & C & C & C & c & C & c & & C & c & B. & c & D & D & D & D \\
\hline \multirow{8}{*}{ DR-s } & $S 35 t$ & C & c & $x$ & c & & & & c & C & C & C & & R & C & c & c & & R. & c & D & & C & & C \\
\hline & $S 41 j$ & C & C & c & $x$ & c & c & C & & c & c & C & D & C & c & C & C & D & & C & D & $\mathrm{B}=$ & C & D & C \\
\hline & $S 28 j$ & C & c & & $\vec{H}$ & C & c & & c & c & & D & D & D & C & c & D & C & C & & D & c & D & & c \\
\hline & $S 43 j$ & c & c & c & C & c & $x$ & c & C & c & D & c & C & c & $x$ & C & C & P & R & 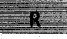 & & C & C & D & c \\
\hline & S3It & c & c & C & C & c & C & C & C & D & C & c & & c & D & R. & $\mathbf{R}$ & & D & C & c & & C & c & C \\
\hline & S30t & $x$ & c & c & C & c & c & c & $\mathrm{R}$ & $C$ & & C & & c & c & $\mathrm{R}$ & B & C & C & A & $c$ & C & & $x$ & $\mathrm{k}$ \\
\hline & $S 2 I t$ & c & C & c & R & C & C & C & c & R & C & D & & D & 하 & $x$ & 8 & & R & & 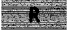 & C & $x$ & & D \\
\hline & $S 25 j$ & C & c & C & C & $\mathrm{R}$ & $\mathrm{A}$ & $\mathrm{A}$ & C & C & C & c & C & C & 8 & C & $\mathrm{R}$ & C & C & C & C & C & D & II & \\
\hline
\end{tabular}

Fig. 1 Dominance relationships between Brassica campestris $S$-alleles in the stigma. CD-s and DR-s represent the codominant-stigma group and the dominant/recessive-stigma group, respectively. Symbol 'C' represents the codominant combination between left and upper $S$-alleles. ' $\mathrm{D}$ ' and ' $\mathrm{R}$ ' indicate that the left $S$-allele is dominant and recessive to the upper one, respectively. Asterisk and ' $\mathrm{X}$ ' show independent weakening and nondeterminable combinations, respectively. 
homozygotes (Table 2). This may indicate low expressivity of $S$-genes in a heterozygous plant. A similar phenomenon has been pointed out in B. oleracea by Visser et al. (1982), who described it as 'independent weakening', e.g. the cross $S_{a} S_{a} \times S_{a} S_{b}$ is compatible and $S_{b} S_{b} \times S_{a} S_{b}$ is more or less compatible, but on selfing the heterozygote is incompatible. These $S$-combinations are indicated by an asterisk in Figs 1 and 2.

\section{Dominance relationships in the stigma and the pollen}

The $24 S$-alleles could be classified into two groups according to the pattern of their dominance relationships in the stigma (Fig. 1). Sixteen of the alleles were assigned to a codominant-stigma (CD-stigma) group, because each of them was codominant to each other. The other eight $S$-alleles were assigned to a dominant/recessive-stigma (DR-stigma) group, because they were either codominant, dominant or recessive to the members of the CD-stigma group as well as to the other members within the DR-stigma group. We could not find any consistency in the relationships between the alleles within the DR-stigma group except that $S_{28}$ was always codominant or dominant to the other $S$-alleles. The two $S$-pairs, $S_{28} S_{36}$ and $S_{21} S_{45}$, showed independent weakening.

In the pollen, $11 S$-alleles were assigned to the CD-pollen group and nine $S$-alleles to the DR-pollen group, which are comparable to the two stigma groups in terms of codominance and dominance (Fig. 2). A further four $S$-alleles were generally recessive to the members of the other two groups and were therefore assigned to the recessivepollen (R-pollen) group.

It is clear that the dominance relationships of $S$-alleles are different in the stigma and the pollen as shown in Figs 1 and 2, because the $S$-alleles classified into the CD-stigma and the DR-stigma groups do not correspond to the $\mathrm{CD}$ and DR groups in the pollen. Of the four $S$-alleles in the R-pollen group $\left(S_{31}, S_{40}, S_{44}\right.$ and $\left.S_{29}\right)$, one $\left(S_{31}\right)$ belonged to the DR-stigma group, and the other three to the CD-stigma group. The $S$-alleles examined were

\begin{tabular}{|c|c|c|c|c|c|c|c|c|c|c|c|c|c|c|c|c|c|c|c|c|c|c|c|c|c|}
\hline & \multicolumn{11}{|c|}{ CD-p } & \multicolumn{9}{|c|}{ DR-p } & \multicolumn{4}{|c|}{ R-p } \\
\hline & & $S 45 j$ & $S 24 j$ & $S 37 j$ & $S 43 j$ & $S 26 j$ & $S 38 t$ & $S 28 j$ & $S 34 j$ & $S 41 j$ & $S 48 t$ & $S 46 j$ & $S 25 j$ & $S 47 t$ & $S 32 t$ & $S 35 t$ & $S 49 t$ & S30t & S21t & $S 33 t$ & $S 36 j$ & S3It & $S 44 j$ & $S 40 t$ & $S 2 q_{j}$ \\
\hline \multirow{11}{*}{ CD-p } & $S 45 j$ & & c & c & $x$ & C & c & c & c & c & c & c & c & & c & c & c & D & D & D & c & it & D & D & D \\
\hline & $S 24 j$ & c & & c & c & C & c & c & c & c & C & C & c & & c & c & C & D & D & $x$ & $x$ & th & मे & D & D \\
\hline & $S 37 t$ & c & c & & c & C & C & c & c & c & C & & C & c & C & & c & C & D & $x$ & c & it & D & D & D \\
\hline & $S 43 j$ & $x$ & c & c & & C & c & c & $x$ & c & c & c & c & c & D & c & c & c & D & c & c & D & D & D & D \\
\hline & $S 26 j$ & c & c & c & c & & C & C & c & C & c & C & C & D & D & D & $x$ & c & $x$ & c & c & D & D & D & D \\
\hline & $S 38 t$ & c & c & c & c & C & & C & c & c & c & & D & & c & & c & C & c & C & c & D & D & D & D \\
\hline & $S 28 j$ & c & c & c & C & C & c & & c & C & c & c & $x$ & & & c & & D & & c & c & it & D & D & D \\
\hline & $S 34 j$ & c & c & C & $x$ & C & C & c & & C & C & C & c & c & c & $x$ & c & D & $x$ & c & D & D & D & D & D \\
\hline & $S 41 j$ & C & c & c & C & C & C & c & c & & C & C & c & C & c & D & D & c & D & & $x$ & $\Delta$ & D & D & D \\
\hline & $S 48 t$ & C & c & c & c & C & c & C & c & c & & & c & $x$ & C & c & C & c & D & c & $x$ & D & D & D & D \\
\hline & $S 46 j$ & C & C & & C & C & & C & C & C & & & C & & & & & & & & $x$ & & D & & D \\
\hline \multirow{9}{*}{ DR-p } & $S 25 j$ & C & c & c & c & C & $B$ & c & c & C & C & c & & c & C & c & D & D & D & c & c & D & D & D & D \\
\hline & $S 47 t$ & & & c & C & P & & & c & C & $x$ & & c & & & & $x$ & c & c & C & D & D & c & D & D \\
\hline & $S 32 t$ & C & c & c & $R$ & $\bar{A}$ & c & & c & C & C & & c & & & c & c & & $x$ & c & c & D & D & D & D \\
\hline & $S 35 t$ & c & C & & c & R: & & C & $x$ & R & C & & C & & c & & $x$ & c & & th & D & & D & D & मे \\
\hline & $S 49 t$ & C & $c$ & $c$ & c & $x$ & c & & C & R: & c & & R & $x$ & c & $x$ & & c & D & C & D & D & D & D & D \\
\hline & S30t & $R$ & $R$ & C & C & C & c & $R$ & $\mathrm{R}$ & c & C & & \& & c & & c & c & & मे & D & c & D & मे & D & मे \\
\hline & $S 21 t$ & $\mathrm{R}$ & $\mathrm{R}$ & $\mathrm{R}$ & It & $x$ & C & & $x$ & R & $R$ & & h & c & $x$ & & Bn & th & & D & th & it & it & th & it \\
\hline & $S 33 t$ & A & $x$ & $x$ & c & c & c & C & C & & c & & C & c & c & मे & C & R & $\mathrm{B}$ & & c & D & th & th & D \\
\hline & $S 36 j$ & C & $x$ & $C$ & C & C & C & C & $\mathrm{P}$ & $x$ & $x$ & $x$ & C & B & C & A & R & C & 出 & C & & D & D & D & D \\
\hline \multirow{4}{*}{ R-p } & S31t & 4 & 4 & 4 & R & B & $R$ & 4 & $B$ & 4 & A & & $B$ & B & A & & 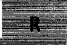 & $R$ & 4 & $\mathrm{R}$ & $\mathrm{R}=$ & & D & 4 & 4 \\
\hline & $S 44 j$ & R & น & R & $\mathrm{R}$ & A & $\mathrm{R}$ & $\mathrm{R}$ & 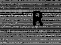 & $\mathrm{R}$ & $\mathrm{R}$ & R & R & C & A & R & R & is & t5 & t & A & $\mathrm{A}=$ & 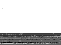 & D & D \\
\hline & $S 40 t$ & $R$ & R & R. & $R$ & I & $\mathrm{R}$ & $\mathrm{R}$ & $R$ & $=8-$ & $-B$ & & R & A & A & Al & a & B & tै & t5 & $R$ & it & \& & & D \\
\hline & $S 2 g_{j}$ & R & A & 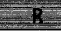 & $R=$ & R & R & A & $\mathrm{R}$ & A & $\mathrm{R}=$ & A & R & R & $\mathrm{A}$ & t5 & A. & से & is & R & R & it & R & R & \\
\hline
\end{tabular}

Fig. 2 Dominance relationships between Brassica campestris $S$-alleles in the pollen. CD-p, DR-p and R-p represent the codominant-pollen group, the dominant/recessive-pollen group and the recessive-pollen group, respectively. (Explanation of symbols is described in Fig. 1.) 
originally numbered according to the isoelectric (pI) point of their SLG ( $S$-locus glycoprotein) (Nou et al., 1993b). There is, however, no correlation between the dominance relationships of their alleles in the stigma and the pI values of their SLG products.

Another characteristic feature of the pollen was that the $S$-alleles of the CD-pollen group were either codominant, or dominant to those of the DR-pollen and the R-pollen groups; no recessive pair was found in the upper right quarter in Fig. 2. In contrast, in the stigma, the $S$-alleles of the CD-stigma group were either codominant, or recessive to those of the DR-stigma group. Thompson \& Taylor (1966) pointed out that nonlinear relationships were common in B. oleracea. They also appear to be common in $B$. campestris, where nonlinear relationships were observed more frequently in the stigma (30.1 per cent: 464 nonlinear dominance/1493 all possible triplets of $S$-alleles) than in the pollen (17.7 per cent: 175/988). In the stigma, two $S$-alleles, $S_{21}$ and $S_{25}$, were frequently associated with nonlinear dominance. In the pollen, five $S$-alleles, $S_{21}$,
$S_{25}, S_{30}, S_{32}$ and $S_{33}$, were strongly associated with nonlinear dominance.

Independent weakening and nondeterminable $S$-combinations were observed more frequently in the pollen than in the stigma. Independent weakening was observed in two combinations within the R-pollen group, in nine between the DR-pollen and the R-pollen groups, and six between the CD-pollen and the R-pollen groups. The independent weakening seems to be correlated with recessiveness of $S$-alleles.

The dominance relationships so far described were determined by the results obtained from testcrosses between $F_{1}$ plants and their homozygous parents. We examined an $\mathrm{F}_{2}$ family produced by bud-selfing an $\mathrm{F}_{1}, S_{24} S_{25}$, to confirm the classification of the alleles. The test-cross of $S_{24} S_{25}$ against its parents showed that $S_{24}$ was codominant to $S_{25}$ in the pollen, but $S_{24}$ was dominant to the $S_{25}$ in the stigma (Figs 1 and 2). The $\mathrm{F}_{2}$ progeny of the $\mathrm{F}_{1} S_{24} S_{25}$ were classified into three groups according to their pollen tube behaviour by making the diallel pollination among them (Fig. 3). The dominance relationships

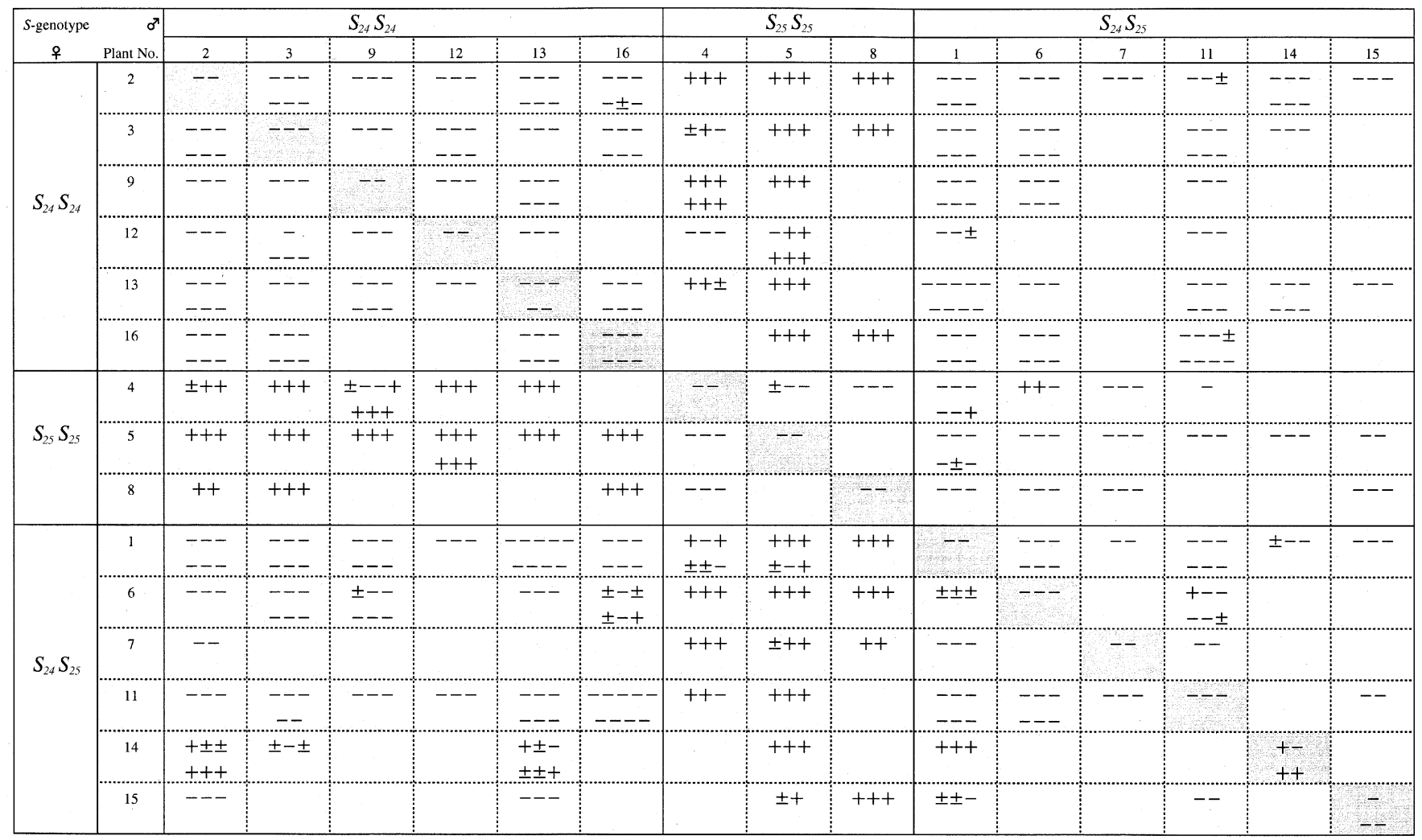

Fig. 3 Results of diallel pollinations between plants of a Brassica campestris $\mathrm{F}_{2}$ family segregating for $S_{24}$ and $S_{25}$. Compatible, incompatible and partially compatible pollinations are shown by,+- and \pm , respectively. 
determined by their diallel crosses confirmed the results obtained from the $F_{1}$ test-cross experiment.

\section{Discussion}

Dominance relationships have been analysed in several species of Brassicaceae, including $B$. oleracea (Thompson, 1956; Thompson \& Taylor, 1966; Ockendon, 1975; Wallace, 1979; Visser et al., 1982), B. campestris (Mackay, 1977), Iberis amara (Bateman, 1954, 1955), Raphanus raphanistrum (Sampson, 1964, 1967) and Sinapis arvensis (Stevens \& Kay, 1989). The data presented here are similar to those of these previous studies in the following three ways. First, codominant relationships are more frequent than dominant/recessive ones in both the stigma and the pollen. Secondly, dominance occurs more frequently in the pollen than in the stigma. Thirdly, alleles which are dominant to others in the stigma are not necessarily dominant to the same alleles in the pollen. These features can be considered as a characteristic of self-incompatibility in Brassica species.

In Ipomoea trifida (Convolvulaceae), which also possesses a one-locus, multiallelic sporophytic selfincompatibility system, about 90 per cent of 326 allelic pairs examined displayed dominance both in the stigma and the pollen, and there was a high degree of linearity between six groups of alleles (Kowyama et al., 1994). By contrast, in Brassica species, nonlinear dominance is observed in both stigma and pollen, but it is more frequent in the stigma, as found in the present experiment.

Another feature of self-incompatibility in Brassica is that some $S$-allelic combinations show low expressivity of $S$-genes in a heterozygous plant. This resembles the independent weakening described by Visser et al. (1982), by which the activity of both alleles is weakened in a heterozygote, but the selfing of the heterozygote is incompatible. A similar, but a slightly different, case was described in $B$. oleracea var. acephala as mutual weakening, in which the activity of alleles was weakened in a heterozygote, and the selfing of the heterozygote was compatible (Thompson, 1972). In the present study, mutual weakening was not observed because all the heterozygotes were self-incompatible, but independent weakening was found in both stigma and pollen. In the stigma, only two cases were observed. Of 20 cases in the pollen, $S_{21}$ was involved in six cases and $S_{31}$ in eight cases. Detailed analysis of these exceptions may be important for understanding molecular recognition in self-incompatibility.
In this experiment, dominance relationships could not be determined for 4.4 per cent of the $S$-combinations in the stigma and 6.8 per cent in the pollen. The presence of 'leaky' expression of selfincompatibility was noted in wild populations of Sinapis arvensis by Stevens \& Kay (1989). Nou et al. (1991, 1993a) also reported that there were some compatible plants (5-13 per cent) in wild populations of B. campestris. Further analysis of these selfcompatible plants showed that their descendants tended to be self-incompatible and it was difficult to select for self-compatibility (data not shown). The occurrence of such leaky incompatibility seems to be a common feature of self-incompatibility in this taxon. In connection with such leaky incompatibility, it could be considered that the self-incompatibility determined by $S$-alleles in sporophytic action might be modified by the presence of a second gene, $G$, in gametophytic action, as proposed by Lewis (1994). To detect such $G$ genes, because of their low frequency, further investigation may be needed with refined materials, cross combination and the marking of $S$ with $S L G$ or $S R K$.

To date, two genes, $S L G$ ( $S$-locus glycoprotein) and $S R K$ ( $S$-receptor kinase), have been shown to be completely linked to the $S$-locus in Brassica, and are considered to be involved in the recognition reaction of self-incompatibility (reviewed by Hinata et al., 1993; Nasrallah \& Nasrallah, 1993). So far two proposals have been published on the relationships between these genes and dominance. Extremely high degrees of homology between $S L G$ and the $S$-domain of $S R K$ have been found in the dominant $S$-alleles of B. campestris (Watanabe et al., 1994). $S L G$ genes were classified into two groups, class I which correlate to dominant $S$-alleles in the pollen and class II to recessive ones in the pollen. The deduced amino acid sequence homology of $S L G \mathrm{~s}$ within class I or class II is about 80 per cent, but that of $S L G$ s between the two classes was only 65 per cent (Nasrallah \& Nasrallah, 1993). Similar trends to the latter seem to exist between the $S$-alleles in B. campestris, and will be reported elsewhere.

Of the $24 S$-alleles investigated in this study, about 17 per cent were classified as pollen recessives, which is similar to the proportion of pollen recessives in Sinapis arvensis, Brassicaceae (Stevens \& Kay, 1989). In contrast, 10.7 per cent of all investigated $S$-alleles were classified as pollen recessives in cultivars of Brussels sprouts, B. oleracea (Ockendon, 1974). This difference in the frequency of recessive $S$-alleles might result from the nature of the populations investigated; $S$. arvensis and $B$. campestris are 
wild populations, whereas Brussels sprouts are cultivars.

\section{Acknowledgements}

We thank Dr M. J. Lawrence for helpful comments and for improving the manuscript. This work was supported in part by Grants-in-Aid for Special Research on Priority Areas (nos 07281102 and 07281103; Genetic Dissection of Sexual Differentiation and Pollination Process in Higher Plants) from the Ministry of Education, Science, Culture and Sports, Japan. We wish to thank Toru Ono and Go Suzuki for helpful comments and criticism.

\section{References}

BAteman, A. J. 1954. Self-incompatibility systems in angiosperms. II. Iberis amara. Heredity, 8, 305-332.

BAtEMAN, A. J. 1955. Self-incompatibility systems in angiosperms. III. Cruciferae. Heredity, 9, 52-68.

HARUtA, T. 1962. Studies on the genetics of self- and cross-incompatibility in cruciferous vegetables. Res. Bull. No.2, Takii Pl. Breeding Exp. Sta., Kyoto, Japan, $67 \mathrm{pp}$.

HINATA, K., WATANABE, M., TORIYAMA, K. AND ISOGAI, A. 1993. A review of recent studies on homomorphic selfincompatibility. Int. Rev. Cytol., 143, 257-296.

KHO, Y. O. AND BAER, J. 1968. Observing pollen tubes by means of fluorescence. Euphytica, 17, 298-302.

KOWYAMA, Y., TAKAHASI, H., MURAOKA, K., TANI, T., HARA, K. AND SHIOTANI, I. 1994. Number, frequency and dominance relationships of $S$-alleles in diploid Ipomoea trifida. Heredity, 73, 275-283.

LEWIS, D. 1994. Gametophytic-sporophytic incompatibility. In: Williams, E. G., Clarke, A. E. and Knox, R. B. (eds) Genetic Control of Self-Incompatibility and Reproductive Development in Flowering Plants, pp. 88-101. Kluwer Academic Publisher, Netherlands.

MACKAY, G. R. 1977. A diallel cross method for the recognition of $S$ allele homozygotes in turnip, Brassica campestris L. ssp. rapifera. Heredity, 38, 201-298.

NASRAllah, J. B. AND NASRAllah, M. E. 1993. Pollenstigma signaling in sporophytic self-incompatibility response. $\mathrm{Pl}$. Cell, 5, 1325-1335.

NOU, I. S., WATANABE, M., ISOGAI, A., SHIOZAWA, H., SUZUKI, A. AND HINATA, K. 1991. Variation of $S$-alleles and S-glycoproteins in a naturalized population of selfincompatible Brassica campestris L. Jap. J. Genet., 66, 227-239.
NOU, I. S., WATANABE, M., ISUZUGAWA, K., ISOGAI, A. AND HINATA, K. 1993a. Isolation of $S$-alleles from a wild population of Brassica campestris L. at Balcesme, Turkey and their characterization by S-glycoproteins. Sex. Plant Reprod., 6, 71-78.

NOU, I. S., WATANABE, M., ISOGAI, A. AND hinAtA, K. 1993b. Comparison of $S$-alleles and S-glycoproteins between two wild populations of Brassica campestris in Turkey and Japan. Sex. Plant Reprod., 6, 79-86.

OCKENDON, D. J. 1974. Distribution of self-incompatibility alleles and breeding structure of open-pollinated cultivars of Brussels sprouts. Heredity, 33, 159-171.

OCKENDON, D. J. 1975. Dominance relationships between $S$-alleles in the stigma of Brussels sprouts (Brassica oleracea var. gemmifera). Euphytica, 24, 165-172.

SAMPSON, D. R. 1964. A one-locus self-incompatibility system in Raphanus raphanistrum. Can. J. Genet. Cytol., 6, 435-445.

SAMPSON, D. R. 1967. Frequency and distribution of selfincompatibility alleles in Raphanus raphanistrum. Genetics, 56, 241-251.

STEVENS, J. P. AND KAY, Q. O. N. 1989. The number, dominance relationships and frequencies of self-incompatibility alleles in a natural population of Sinapis arvensis L. in South Wales. Heredity, 62, 199-205.

THOMPSON, K. F. 1956. Self-incompatibility in marrow-stem kale, Brassica oleracea var. acephala. I. Demonstration of a sporophytic system. J. Genet., 55, 45-60.

THOMPSON, K. F. 1972. Competitive interaction between two $S$ alleles in a sporophytically controlled incompatibility system. Heredity, 28, 1-7.

THOMPSON, K. F. AND TAYLOR, J. P. 1966. Non-linear dominance relationships between $S$-alleles. Heredity, 21, 345-362.

VISSER, D. L., VAN HAL, J. G. AND VERHOEVEN, W. 1982. Classification of $S$-alleles by their activity in $S$-heterozygotes of Brussels sprouts (Brassica oleracea var. gemmifera (DC.) Schultz). Euphytica, 31, 603-611.

WALlACE, D. H. 1979. Interactions of $S$-alleles in sporophytically controlled self-incompatibility of Brassica. Theor. Appl. Genet., 54, 193-201.

WATANABE, M., TAKASAKI, T., TORIYAMA, K., YAMAKAWA, S., ISOGAI, A., SUZUKI, A. AND HINATA, K. 1994. A high degree of homology exists between the protein encoded by $S L G$ and the $S$ receptor domain encoded by $S R K$ in self-incompatible Brassica campestris L. Pl. Cell Physiol., 35, 1221-1229.

WONG, K. C., WATANABE, M. AND hinAtA, K. 1994. Fluorescence and scanning electron micoroscopic study on self-incompatibility in distylous Averrhoa carambola L. Sex. Plant Reprod., 7, 116-121. 